\title{
Consequences of Metabolic Disruption in Alzheimer's Disease Pathology
}

\author{
J. C. Ryu ${ }^{1}$ - E. R. Zimmer ${ }^{2,3,4,5} \cdot$ P. Rosa-Neto ${ }^{6}$ - S. O. Yoon ${ }^{1}$ \\ Published online: 3 July 2019 \\ (C) The American Society for Experimental NeuroTherapeutics, Inc. 2019
}

\begin{abstract}
Alzheimer's disease (AD) is an irreversible, progressive disease that slowly destroys cognitive function, such as thinking, remembering, and reasoning, to a level that one cannot carry out a daily living. As people live longer, the risk of developing $\mathrm{AD}$ has increased to 1 in 10 among people who are older than 65 and to almost 1 in 2 among those who are older than 85 according to a 2019 Alzheimer's Association report. As a most common cause of dementia, AD accounts for $60-80 \%$ of all dementia cases. $\mathrm{AD}$ is characterized by amyloid plaques and neurofibrillary tangles, composed of extracellular aggregates of amyloid- $\beta$ peptides and intracellular aggregates of hyperphosphorylated tau, respectively. Besides plaques and tangles, AD pathology includes synaptic dysfunction including loss of synapses, inflammation, brain atrophy, and brain hypometabolism, all of which contribute to progressive cognitive decline. Recent genetic studies of sporadic cases of AD have identified a score of risk factors, as reported by Hollingworth et al. (Nat Genet 43:429-435, 2001) and Lambert et al. (Nat Genet 45:1452-1458, 2013). Of all these genes, apolipoprotein E4 (APOE4) still presents the biggest risk factor for sporadic cases of AD, as stated in Saunders et al. (Neurology 43:1467-1472, 1993): depending on whether you have 1 or 2 copies of APOE4 allele, the risk increases from 3- to 12-fold, respectively, in line with Genin et al. (Mol Psychiatry 16:903-907, 2011). Besides these genetic risk factors, having type 2 diabetes (T2D), a chronic metabolic disease, is known to increase the AD risk by at least 2-fold when these individuals age, conforming to Sims-Robinson et al. (Nat Rev Neurol 6:551-559, 2010). Diabetes is reaching a pandemic scale with over 422 million people diagnosed worldwide in 2014 according to World Health Organization. Although what proportion of these diabetic patients develop AD is not known, even if $10 \%$ of diabetic patients develop AD later in their life, it would double the number of $\mathrm{AD}$ patients in the world. Better understanding between $\mathrm{T} 2 \mathrm{D}$ and $\mathrm{AD}$ is of paramount of importance for the future. The goal of this review is to examine our current understanding on metabolic dysfunction in $\mathrm{AD}$, so that a potential target can be identified in the near future.
\end{abstract}

Keywords Alzheimer's disease - Type 2 diabetes · Leptin resistance $\cdot$ Insulin resistance $\cdot$ Circadian rhythm $\cdot$ Brain hypometabolism

S. O. Yoon

sung.yoon@osumc.edu

1 Department of Biological Chemistry \& Pharmacology, Ohio State University, Columbus, OH, USA

2 Department of Pharmacology, UFRGS, Porto Alegre, Brazil

3 Graduate Program in Biological Sciences: Biochemistry, Universidade Federal do Rio Grande do Sul (UFRGS), Porto Alegre, Brazil

4 Graduate Program in Biological Sciences: Pharmacology and Therapeutics, UFRGS, Porto Alegre, Brazil

5 Brain Institute of Rio Grande do Sul (BraIns), Pontifical Catholic University of Rio Grande do Sul, Porto Alegre, Brazil

6 Montreal Neurological Institute, Montreal, Canada

\section{Glucose Hypometabolism in AD}

ApoE4 homozygote individuals exhibit reduced cerebral glucose metabolism in areas classicaly associated with $\mathrm{AD}[50$, 104]. Although the extent of glucose hypometabolism was significantly less in ApoE4 individuals than AD patients, it is noteworthy because these individuals were cognitively normal at the time and were a decade younger than typical age when AD-like symptoms appear. T2D patients also exhibit abberant $\left[{ }^{18} \mathrm{~F}\right]$-fluoro-2-deoxy-2-D-glucose positron emission tomography (FDG-PET) uptake patterns at prediabetic and cognitively normal stages $[4,6,11]$. Alterations of glucose uptake at presymptomatice stages in both $\mathrm{AD}$ and $\mathrm{T} 2 \mathrm{D}$ subjects suggest that metabolic disruption in the brain occurs early in the development of $\mathrm{AD}$ and $\mathrm{T} 2 \mathrm{D}$, and likely to 
contribute to disease progression or pathology. If metabolic disruption plays a disease-modifying role, it can potentially render room for altering diet as a way to influence the disease progression. In Drosophila, increasing energy flux by regulating mitochondrial activity in mushroom bodies that are involved in learning and memory led to improvement in longterm memory [96], suggesting energy metabolism can positively influence memory. Similarly, although the number of patients enrolled was small, individuals diagnosed with MCI and early stages of $\mathrm{AD}$ showed improvement when given special diet that included an increase in ketogenesis [14]. Albeit the fact that the science behind the influcence on brain function of a healthy lifestyle that includes regular exercise and healthier diet is yet to come, these data may be interpreted as suggesting that peripheral energy metabolism can potentially influence higher brain function.

\section{FDG-PET Imaging to Detect Glucose Hypometabolism in AD}

For several decades, FDG-PET imaging has been employed for examining the brains of various dementia and AD patients to study glucose metabolism in the brain. FDG is a short halflife radioactive analog of glucose that is transported into cells but not metabolized beyond the first step of the glycolysis generating FDG-6-phosphate inside the cell. The accumulation of radioactive signals thus reveals the areas in the tissue of interests that are active in glucose metabolism. AD patients present widespread FDG hypometabolism in brain region including parieto-temporal, posterior cingulate, and frontal cortices [22, 85, 86, 88] (Fig. 1A). By contrast, other regions, such as the visual cortex, thalamus, and cerebellum, seem to be preserved [83, 84, 111, 114, 115]. Indeed, FDG-PET hypometabolic signature is highly conserved in typical AD cases [114] as well as in early-onset AD patients [37]. In atypical presentations of $\mathrm{AD}$, this "metabolic signature" is diluted in varied hypometabolic topographical patterns [100].

Since an abnormal reduction in FDG uptake in the brain is detectable decades before symptoms appear [50], efforts have been made to develop it as a predictable "preclinical phase" biomarker [64]. Indeed, APOE4 homozygote individuals exhibited glucose hypometabolism in the same areas that showed a FDG reduction long before they showed symptoms, albeit to a less extent [104]. APOE is a lipid-binding protein that transports cholesterol across different tissues and cells [65], and 1 of its alleles, APOE4, has been identified as a major genetic risk factor for late-onset AD [75]. Having 1 or 2 copies of APOE4 increases the risk of developing AD 3- to 12-fold [69]. Although the use of "preclinical phase" to define this period is gaining acceptance, routine use of FDGPET appears limited in diagnosing asymptomatic individuals as being at risk to develop AD. For instance, representative areas of FDG hypometabolism remains to be determined in amyloid-positive asymptomatic subjects, autosomaldominant Alzheimer's disease individuals, and in subjects presenting subjective cognitive decline [25]. In addition, cortical FDG hypermetabolism in the superior temporal gyrus was reported in cognitively unimpaired (CU) subjects with significant amyloid deposition in superior temporal gyrus [38]. The same pattern of hypermetabolism was also identified in APOE4 carriers in an amyloid status-independent manner [140]. This could be a compensatory mechanism associated with early toxic species of $A \beta$, such as $A \beta$ oligomers that are produced from amyloid precursor protein (APP) following 2-step proteolytic processing at its extracellular and interamembrane domains [112].

Abnormalities in glucose metabolism are, however, not restricted to $\mathrm{AD}$ [49]. As such, the National Institutes on Aging (NIA) and the Alzheimer's Association (AA) incorporated FDG-PET as a biomarker of "neurodegeneration" in the recent research framework, the NIA-AA 2018. FDGPET is in fact being used for differential diagnosis, distinguishing $\mathrm{AD}$ from frontotemporal dementias (FTDs) with high sensitivity and specificity [101]. In addition, a systematic review indicates that FDG-PET can discriminate AD from CU individuals with a pooled sensitivity of $90 \%$ and specificity of $89 \%$. The inclusion of mild cognitive impairment (MCI) subjects, a more heterogeneous group, surprisingly produced only slight variation, modifying sensitivity and specificity values to $92 \%$ and $78 \%$, respectively [10]. These findings indicate that in a large group of subjects, FDG-PET is indeed a good biomarker for discriminating $\mathrm{CU}, \mathrm{MCI}$, and $\mathrm{AD}$ dementia individuals. In smaller groups or at the individual level, the validity of FDG to discriminate MCI patients remains to be determined.

Many in the field are applying FDG-PET to AD mouse models. The miniaturized version of PET, which is termed micro-PET, allows high-resolution noninvasive imaging in small animals, such as rats and mice [34, 63]. Transgenic animal models with pathological mutations in human APP exhibit progressive deposition of $A \beta$ in parallel with cognitive abnormalities and are highly suited for longitudinal assessment with micro-PET [35]. Currently, several studies have used FDG imaging to investigate glucose metabolism in these animal models (for review, see [146]). The FDG patterns in APP mutant mice, however, do not appear to follow exactly what is observed in human cases. For instance, Tg2576 mice that express human APPswe under the Prp promoter exhibit early hypermetabolism at 7 months, but normal FDG patterns at 9-15 months [58, 74, 78]. APPswe/PS1 $\Delta 9$ mice under the Prp promoter also show early hypometabolism at 6 months coinciding with the beginning of amyloid plaque deposition, but normal metabolism at later stages at 13-15 months [103, 143]. These differences may be due to technical challenges that are associated with micro-PET and the small size of the 
Fig. 1 FDG metabolism in Alzheimer's disease continuum and transgenic rats. (A) Axial FDG images of cognitive unimpaired (CU), mild cognitive impaired (MCI), and Alzheimer's disease $(\mathrm{AD})$ individuals.

Standardized uptake value ratio (SUVR) was calculated using the pons as the reference area. (B) Sagittal and coronal FDG images in 11- and 19-month-old McGillR-Thy1-APP transgenic rats. SUVR was calculated using the pons as the reference area

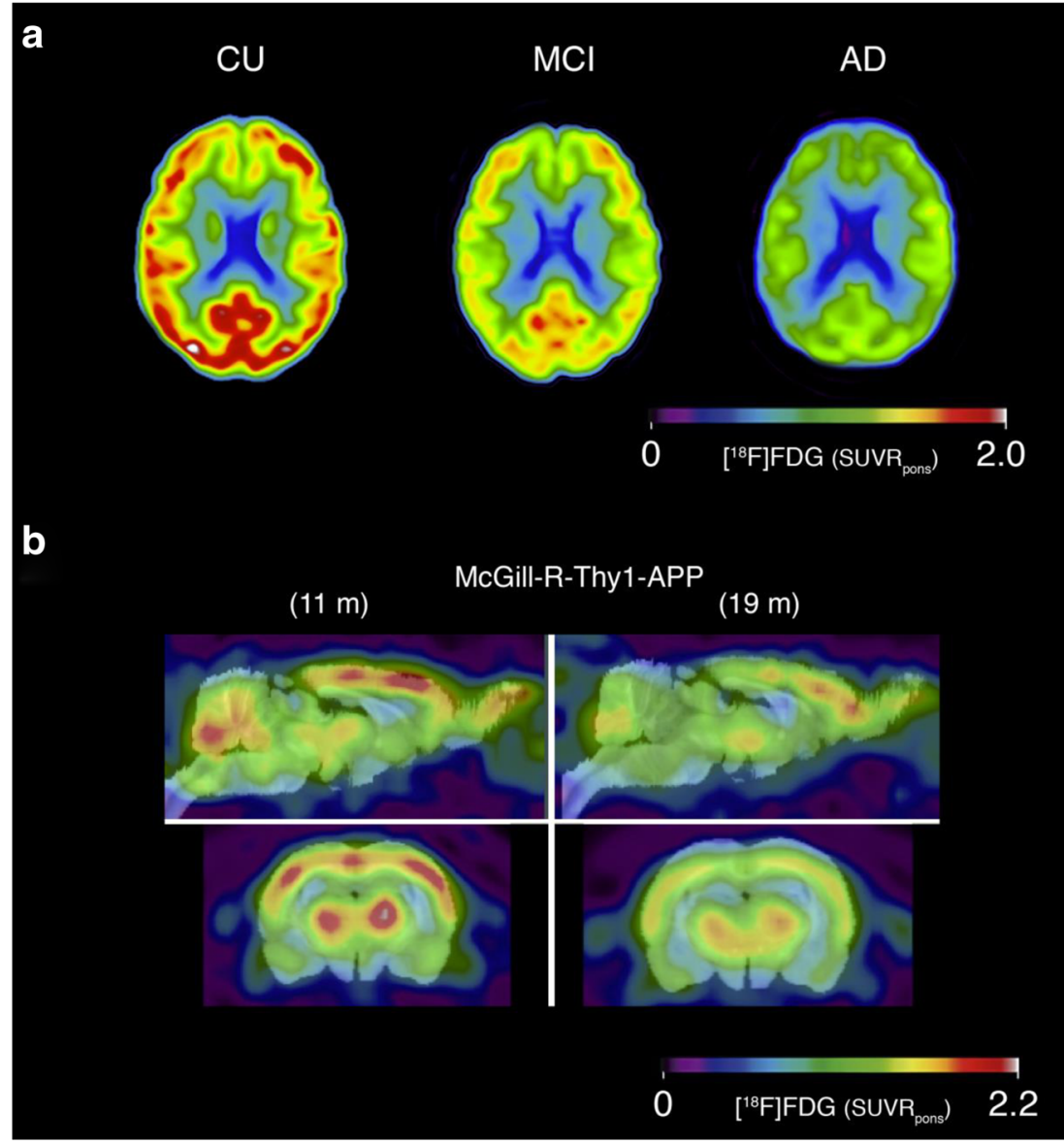

mouse brain [146], or the nature of APP overexpression associated with transgenic mice. If it is due to technical challenges, transgenic rats may be better animal models for micro-PET imaging, due to a larger brain size than mice, such as McGillR-Thy1-APP that expresses human APP751 swe/ind [92] (Fig. 1B).

FDG-PET studies in T2D patients are not numerous, althougth it is well recognized that type 2 diabetes (T2D) patients exhibit regional brain atrophy and cognitive impairment even if they are not necessarily diagnosed as having AD $[1,67,80]$. The reason for the cognitive deficits in T2D patients is unclear, but it is believed to be due to insulin resistance in the brain [70]. Whether glucose metabolism is also reduced in T2D patients is unclear since some studies reported a reduction in FDG uptake [4], while some reported an increase [11]. Also in rodent models, the results are inconsitent: brain glucose metabolism in $\mathrm{db} / \mathrm{db}$ mice was reduced based on $\left[{ }^{3} \mathrm{H}\right]$-2-deoxy-D-glucose or $\left[{ }^{14} \mathrm{C}\right]$-2-deoxy-D-glucose uptake $[31,133]$, while FDG-PET imaging of T2D rat brains showed an increase [6].

Since both $\mathrm{AD}$ and T2D exhibit alterations in glucose metabolism, a hypothesis was proposed that there might be a defect in glucose-sensing machinery of the brain in both AD and T2D [102]. Glucose-sensing neurons and astrocytes in the brain are found in many regions, but they are mostly enriched in the hypothalamus and brain stem $[30,122]$. Regardless of the regions involved, glucosesensing neurons are divided into glucose-excited (GE) ones that increase and glucose-inhibited (GI) ones that decrease their firing rate under hyperglycemic or hypoglycemic conditions, respectively. The mechanisms by which GE neurons sense glucose are diverse, which depends on the type of glucose transporters expressed as well as the presence or absence of ATP-sensitive K channels and glucokinase, the major glucose sensor [122]. For GI neurons, on the other hand, activation of AMP-activated protein kinase (AMPK) appears to play a critical role [18]. Cells of another type in the hypothalamus that are involved in glucose sensing are tanycytes in the medial eminence. Tanycytes are a unique type of ependymal radial glia that participate in the fenestrated capillary barrier, and whose processes traverse various hypothalamic nuclei and surround ventrally located capillaries [26]. Like pancreatic beta cells, tanycytes express Glut 1 and 2 and ATPsensitive $\mathrm{K}$ channels, and respond to glucose puffs [8]. They also express glucokinase that couples the extracellular glucose levels to insulin secretion [79, 127]. But, whether there are significant changes in glucose 
transporter expression or their function among glucosesensing cells of the brain in AD and T2D mouse models are currently unknown.

What is the significance of the reduction in glucose uptake in the brain? Since glucose is taken up by neurons and astrocytes [24, 30, 73, 147], a general hypometabolism of glucose in the brain is believed to represent reduced activities at synapses in these cells. Indeed, when brain glucose levels were increased acutely for $4 \mathrm{~h}$ by approximately 2 -fold via a microdialysis techique coupled to glucose clamps, interstial fluid (ISF) $\mathrm{A} \beta$ levels increased by 25 to $39 \%$ during the hyperglycemic challenge at presymptomatic and symptomatic ages, respectively, in Appswe/PS1 $\triangle \mathrm{E} 9$ mice [76]. Under the same setting, ISF lactate levels increased during hyperglycemic challenge. Since lactate released by astrocytes is shuttled to neurons, the increase in ISF lactate suggests that higher glucose levels in the brain increased neuronal activity [136], although recent studies demonstrated that neurons themselves take up glucose as well [24, 73].

\section{Connection Between AD and T2D}

\section{Insulin Resistance}

In addition to the fact that T2D increases the risk of developing AD later in life at least 2-fold [116], epidemiological studies also indicate a strong connection between AD and T2D both of which exhibit vascular lesions, hyperglycemia, hyperinsulinemia, atherosclerosis, and hypertension [116]. The underlying mechanism linking the 2 chronic diseases, however, remains unknown.

Insulin resistance is 1 of the 2 major cellular and physiological phenotypes characterizing T2D. It was demonstrated that the greater the extent of peripheral insulin resistance was, the lower the glucose uptake was in the brain when a late middle-aged individual cohort that has AD parental history was examined [134]. Contrary to the periphery, however, where glucose uptake is largely insulin dependent, the brain uses nearly $20 \%$ of all glucose in the body in a process that is largely insulin independent: when rats were rendered insulin deficient with streptozotocin treatment that destroys insulinproducing pancreas, intracerebral delivery of leptin restored glucose sensitivity [33]. These results also suggest that leptin in the brain can control blood glucose levels in insulinindependent manner.

Insulin receptor (IR) and insulin-like growth factor (IGF) 1 and 2 receptors are widely expressed in the brain [129, 130] (Allen Brain Atlas). IR and IGF receptors can form heterodimers with each other, which gives them different affinity to different types of ligands, such as insulin, IGF-1, and IGF-2 [57]. When IR was deleted in neurons or astrocytes, insulin resistance ensued suggesting IR is involved in insulin resistance. A neuron-specific knockout of IR study using nestin-cre line demonstrates that mice developed obesity, mild insulin resistance, and demonstrated elevated levels of insulin and leptin in plasma [15]. On the other hand, when IR was deleted in astrocytes using hGFAP-creERT2 and GLASTcreERT2 mice, not only insulin signaling was attenuated, but also glucose uptake [30]. These results suggest that astrocytic IR may participate in developing insulin resistance, but more importantly, it plays a critical role in glucose uptake. It should be noted that hypothalamic tanycytes also express GFAP [106] and become labeled in GLAST-creERT2 mice [105], suggesting it is plausible that tanycyte-mediated glucose uptake contributed to the phenotype.

In AD mouse background, the role of IR signaling appears mixed. When nestin-cre-derived IR null mice were crossed with Tg2576, A $\beta$ peptide levels were reduced with an attenuation in p-AKT and p-GSK3 levels [124], suggesting IR signaling contributed positively to amyloid deposition. When IGF-1 receptor was deleted from APPswe/PS1 $\Delta 9$ mice, however, it resulted in modestly higher scores in cognitive tests, a reduction in astroglyosis and synaptic loss, but increased $A \beta$ aggregation [21], suggesting unlike IR, IGF-1 receptor contributes negatively to the development of $\mathrm{AD}$ pathology. The authors argued that IGF-1 signaling is also involved in defibrillation of $\mathrm{A} \beta$ plaques, but the mechanisms remain to be investigated.

Like the receptor knockout studies, a clear consensus has not been reached as to whether brain insulin levels are indeed elevated and whether insulin resistance is being detected in the brain from AD mouse models as well as in human AD brain samples [120]. For instance, some reported a reduction in $\mathrm{p}$ AKT and p-GSK3 levels [70, 121], downstream effectors of insulin signaling, while others reported an increase [36, 94, 139]. A complicating issue in these studies is that the kinases tested can also be modulated by signals other than insulin/ IGFs, rendering it difficult to assign the observed changes to insulin exclusively. Perhaps most convincing report came from the study that measured direct phosphorylation of IR and its associated IRS-1/2, after stimulating human postmortem tissue explants from $\mathrm{AD}$ and control subjects with insulin [126]. Similarly, Bomfim et al. also reported an increase in pIRS-1 in cynomolgus monkeys following direct infusion of oligomeric $\mathrm{A} \beta$ into their brains for 24 days [12]. The latter report suggests that $A \beta$ peptides themselves signal to activate IR, perhaps initiating insulin resistance as $A \beta$ peptides accumulate. $\mathrm{A} \beta$ peptides also appear to influence metabolic dysruption in a different AD mouse model of 3XTG mice that expresses APPswe, tauP301L under the Thy1.2 promoter in PS1M146V knockin background. Only the female and not male mice developed glucose intolerance and insulin resistance that worsened progressively in correlation with pronounced $A \beta$ deposits [132], suggesting insulin resistance develops with amyloid pathology. 


\section{Leptin Resistance}

Leptin resistance is another cellular and physiological phenotype of T2D that can potentially influence AD pathology [48]. Leptin is a hormone produced by white adipocytes [40] but signals in the hypothalamus after crossing the blood-brain barrier [40]. With obesity, circulating leptin levels increase resulting in hyperleptinemia, which can elicit leptin resistance [28]. When APP23 mice that express APPswe under the mouse Thy 1 promoter were crossed with leptin mutant ob/ ob mice, the mice exhibited glucose intolerance that is worse than ob/ob mice, and also developed insulin resistance at 3 months, well before $\mathrm{A} \beta$ begins to accumulate, while ob/ob mice did not [125]. Already at 2 months, mice exhibited severe cognitive deficits although there was very little $A \beta$ detectable. The authors also crossed the AD mice with NSY mice that develop T2D-like symptoms [113], and a similar phenotype was observed albeit at much attenuated levels. Although the phenotype of premature cognitive deficit can be attributed to obesity-associated pathology, these data clearly highlight the role of leptin in cognition. It also implicates defective leptin metabolism in the development of $\mathrm{AD}$ pathology.

Defective leptin metabolism has actually been shown in $\operatorname{Tg} 2576$, which had lower serum leptin levels at 3 months compared to the wild-type controls [48]. This is in part due to a significant reduction in total body fat, detectable at ages younger than 2 months old in Tg2576 mice. Since Tg2576 mice do not show plaques until they are 11-13 months old, these data illustrate the presence of an early metabolic disruption in the mice. Correlative to low serum leptin levels, Tg2576 mice appear to have a functional defect in the hypothalamus; their fasting glucose levels are higher than in the wild-type mice, and fasting-induced increase in NPY and AgRP RNAs was completely lost in Tg2576 mice. NPYpositive arcuate neurons from $\mathrm{Tg} 2576$ mice also failed to respond to leptin electrophysiologically, and the authors demonstrated this was likely due to $A \beta 42$ interfering with leptin action. In line with these data, we found that 5XFAD mice exhibit leptin resistance at 6 months even on normal chow but not insulin resistance, unless fed with $60 \%$ high-fat diet (HFD, Fig. 2, insulin resistance not shown). Whether leptin levels are altered in human $\mathrm{AD}$ cases, on the other hand, is not conclusive: higher cerebrospinal fluid (CSF) leptin levels were reported in $\mathrm{AD}$ subjects without any correlation with BMI [13], but serum leptin levels were lower in $\mathrm{AD}$ cases compared to control individuals [97].

If $A \beta 42$ indeed interferes with leptin signaling, the mechanism by which $A \beta 42$ inhibiting leptin signaling needs to be elucidated. If the phenotype is due to an inhibitory crosstalk between the $A \beta 42$ and leptin signaling pathways, potential targets should be those that are modulated by both $A \beta 42$ and leptin. A candidate is AMP-activated protein kinase
(AMPK), since A 342 activates AMPK [77, 128, 142], while leptin inhibits it [82]. Indeed, AMPK phosphorylation was increased in APP/PS2 mice that express hAPPswe and hPS2-N141I under the Thy1 and Prp promoters, respectively [71], as well as in APPsw/PS1 $\triangle$ E9 mice under the Prp promoter [118]. We have also found that AMPK activity is significantly increased in 5XFAD mice (data not shown), which increases further with HFD. Although the fact that an increase in AMPK activity is observed in multiple AD models is encouraging in placing the focus on AMPK as the putative target of leptin resistance, the role of AMPK activation and leptin resistance itself in overall AD pathology needs to be fully examined.

The transport of leptin into the brain constitutes an important part of leptin metabolism since leptin acts mostly in the brain. Leptin is produced from adipocytes and transported into the brain through microvessles and the fenestrated barrier in the medial eminence. Studies that utilized targeted leptin receptor knockout mice suggest that the leptin receptor itself is involved in leptin uptake. When leptin receptor was deleted in endothelial cells using Slcolc1-creERT2 line, ${ }^{125}$ I-leptin uptake was reduced by $60 \%$ in the cortex and ventral tegmental area, and $\sim 40 \%$ in the hypothalamus, reflecting $50 \%$ reduction in leptin receptor RNA detected in the brain [23]. In the global leptin receptor knockout mice, however, leptin uptake was reduced only by $40 \%$ [43]. It is possible that the discrepancy is due to some leptin molecules crossing the blood-brain barrier that does not rely on endothelial cells, such as the fenestrated barrier of the arcuate and medial eminence. Tanycytes in the medial eminence were shown to take up leptin both in vitro and in vivo [5], which were not targeted in endothelial deletion of the leptin receptor.

Whether leptin levels are altered in human AD subjects is not completely settled. In a 9-year follow-up study of elderly patients, it was found that the higher the serum leptin levels were, the lower the risk of developing dementia and $\mathrm{AD}$ [68]. Similar results were also reported by others $[9,44,51,56]$. In contrast, other groups reported that lower serum leptin levels were associated with cognitive impairment in T2D patients, and that leptin levels in the CSF and plasma were higher in $\mathrm{AD}$ and dementia patients [141] and a significant increase in CSF leptin levels among AD cases [13]. The reasons for the opposite results are not clear at the present time.

\section{Disruption in Circadian Rhythm}

It has been reported since the early 1980s that AD patients experience disturbed sleep, which is now being called as "sundowning" behavior [98, 99]. Disruption in circadian rhythm (CR) can have significant influence in overall metabolic balance [27]. There is a strong correlation between circadian disruption and cardiovascular disease, obesity, and 


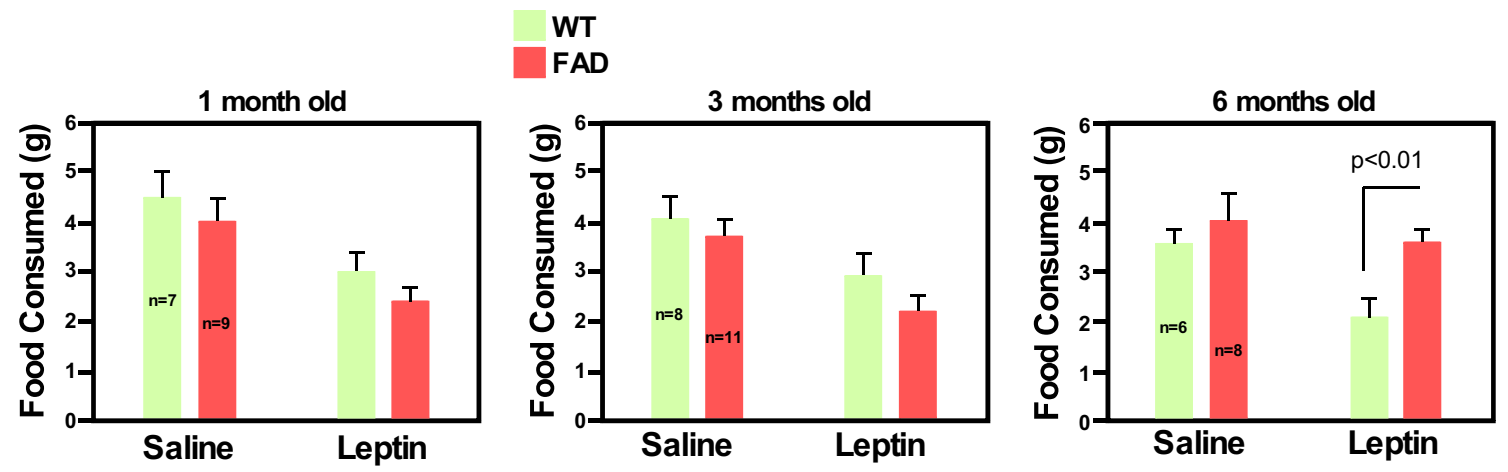

Fig. 2 XXFAD mice develop leptin resistance at 6 months on normal chow. 5XFAD mice were subjected to leptin sensitivity assay by measuring 24-h food consumption after $5 \mathrm{mg} / \mathrm{kg}$ of human leptin injection

hyperglycemia, as observed among individuals who work on the night shift $[54,55,93,131]$. In addition, expression levels of many metabolic enzymes as well as proteins involved in detoxification and stress responses cycle according to CR. Some of these include glucose transporter, glucokinase, glucagon, pyruvate kinase, acyl CoA dehydrogenase, aldehyde dehydrogenase, fatty acid synthase, glycogen phosphorylase, nicotinamide phosphoribosyltransferase, and AMPK [19, 29, $59,60,66,91]$. Levels of $A \beta$ peptides and tau in the brain also fluctuate according to CR, suggesting CR influences APP and tau metabolism.

Recent research demonstrates a clear link between disturbed sleep and accumulation of $\mathrm{A} \beta$ peptides and tau. For instance, disrupting normal sleep in mice led to a 2-fold increase in ISF tau [46]. An increase in tau in CSF was also observed in humans by sleep intervention. Similarly to tau release, $A \beta$ peptide levels increased upon sleep deprivation both in mouse ISF and human CSF upon sleep perturbation $[53,72,107]$.

ISF and CSF A $\beta$ peptides are known to cycle according to diurnal patterns both in rodents and humans [53]. Since administration of tetrodotoxin (TTX) that blocks sodium channel reverses the increase in ISF $\mathrm{A} \beta$, it is hypothesized that neuronal activity is responsible for the increased release of $\mathrm{A} \beta$ peptide at nighttime. The link between neuronal activity and an increase in ISF A $\beta$ and APP processing has been demonstrated [20,52]. What would be the basis for increased neuronal activity in synaptopathic diseases such as AD? It was reported that although there were general depression in excitatory $\mathrm{Ca}_{2}{ }^{+}$transients in APP23:PS45 mice compared to the wild-type controls, a group of neurons that were located within $60 \mu \mathrm{m}$ from amyloid plaques exhibited a surprising hyperactivity [16]. The hyperactivity was attributed to defective GABAnergic synaptic inhibition based on pharmacological studies [16]. These results may lend support for the observation that epileptic seizures are more common among AD patients [2, 41, 42, 81, 90, 108, 110]. If abberrant seizure-like activity is prevalent in $\mathrm{AD}$ brains, one can envision that such activity can deliver stimuli that ultimately leads to accumulation of $A \beta$ peptides. Whether ISF $A \beta$ peptides are released preferentially from plaque-associated ones is unknown, and so is the question whether $A \beta$ released upon neuronal activity is in some way related to hyperactive neurons: increasing neuronal activity facilitates cleavage of APP [52]. Could sleep deprivation increase perhaps aberrant or excessive neuronal activity like epileptic seizures at night? It is noteworthy that when mice were optogenetically stimulated in the perforant pathway to provide chronic neuronal activation, they exhibited seizure soon after each optogenetic stimulation [138]. These data suggest that the intensity of neuronal activity evoked by experimental stimulation paradigm is higher than normal neuronal activity. Whether seizure occurrences are higher at night in $\mathrm{AD}$ patients is currently not known.

An alternative explanation for the link between sleep deprivation and increased $A \beta$ and tau release in ISF and CSF may be that sleep deprivation inhibits efficient disposal of $A \beta$ peptides, since glymphatic system becomes more efficient during sleep by creating convective fluxes in periarterial space [137]. Decreased disposal of $A \beta$ peptides upon sleep disturbances also provide explanation to the observed correlation between lower CSF A $\beta 42$ and rapid progression of dementia [117]. It is unlikely, however, that reduced ISF tau disposal underlies the increased CSF tau levels, since the higher CSF tau correlates with more severe dementia in humans [117].

When sleep is disturbed, it also disrupts our normal CR. It is well known that there is a strong connection between the $\mathrm{CR}$ and metabolism. The central clock in suprachiasmatic nucleus (SCN) is influenced by internal metabolite levels including blood glucose and lipids [7, 89]. The identity of metabolic nutrient sensors that are coupled to the CR is currently unknown, but the focus is on AMPK and the pathway involving $\mathrm{NAD}^{+} /$Sirt1 metabolism, since both AMPK and Sirt1 activities are regulated by the clock as well as nutritional status [7]. AMPK phosphorylates crytochorme, Cry, directly [62]. Accordingly, the CR in the liver of LKB1 knockout mice is disrupted. LKB1 is not the upstream kinase for AMPK in the brain [135], but the identity of a kinase that phosphorylates 
and activates AMPK in the brain in a CR-dependent manner is yet to be deterimined. Sirtuins are part of a feedback loop with the core clock in NAD-dependent manner [3, 87]. ClockBMal1 in turn activates the genes involved in NAD+ synthesis, whose cellular concentration cycles in alignment with the CR.

It should be added here that AD transgenic mice are known to exhibit a disrupted CR. 5XFAD mice exhibited dramatic alterations in the CR at 8 months of age, but even at 2 months, BMal1 and Per2 RNA levels in the SCN began to lose daily oscillations [119]. The difference was attributed to $A \beta$ inducing degradation of BMal1 in the nucleus, thereby inhibiting Per2 induction. Also in 3xTg-AD mice, CR was disrupted [123]. Whether $A \beta$ is responsible in disrupting the $C R$ is unclear, and neither the mechanism by which $A \beta$ signals to induce degradation of clock proteins, especially because APOE null mice also exhibited a defect in the CR [145]. Nonetheless, these studies suggest that restoration of normal CR can certainly be a way to improve metabolic imbalances, which would have positive impact on certain aspects of $\mathrm{AD}$ pathology.

\section{Metabolic Disruption in AD Brains}

The literature clearly suggests a metabolic dysfunction exists in AD brains, and it begins long before syptoms appear. But, there are many outstanding questions that need to be addressed. What cellular processes or molecules are responsible for initiating metabolic disruption? What are the consequences of metabolic disruption in AD brains? Does peripheral metabolic dysfunction influence the brain metabolism? If so, what is the underlying mechanism? Can we reverse the metabolic defect with diet?

Of the mutations that confer increased susceptability for developing AD [61], ApoE and perhaps clusterin, may be more relevant to understanding metabolic dysfunction in $\mathrm{AD}$, since both are lipid-binding proteins. ApoE4 homozygosity in particular presents the greatest genetic risk for late-onset $\mathrm{AD}$, and $50-60 \%$ of $\mathrm{AD}$ cases harbor either 1 or 2 copies of ApoE4 alleles [47]. Individuals who are homozygous for E4 alleles are 12 times more likely to develop AD, and those who are heterozygotes, 3.7 times [120]. Glucose hypometabolism in their brain is detectable very early long before cognitive impairment surfaces [104]. The risk of developing cerebral amyloid angiopathy (CAA) is also much higher among ApoE4 carriers with T2D than those with diabetes or E4 alone [95]. ApoE4 is also hypothesized to be the critical molecule that could relay the peripheral insulin metabolism to the CNS: when ApoE3 and ApoE4 knockin mice were rendered insulin resistant in the periphery by HFD, there was a reduction in $\mathrm{p}$ AKT and p-GSK3 in the hippocampus and cortex from ApoE4- but not in ApoE3-KI mice, suggesting that ApoE4 may be involved in conveying peripheral insulin resistance to the brain [144]. Insulin-mediated AKT activation via infusion with reverse microdialysis was also attenuated in greater extent in ApoE4 compared to ApoE3 knockin mice, mainly due to ApoE4 interfering with recycling of the IR to the neuronal surface. Whether there exists a crosstalk between ApoE4 and leptin signaling has not been tested. Of note, clusterin was shown to augment leptin signaling in the hypothalamus [17].

\section{Concluding Remarks}

Recent analyses of human AD brain samples revealed that $\mathrm{AD}$ is a complex disease with many comorbities associated with it [39]. To better combat AD, we need a greater understanding of the disease progression in human cases not only in $\mathrm{AD}$ but also other diseases that exhibit similar comorbidities that are linked to AD. For instance, although some in the field begin to name $\mathrm{AD}$ a type 3 diabetes due to metabolic disruption observed in the AD brain [121], only limited data are currently available on FDG-PET from T2D patients at presymptomatic stages. Progress in therapy will be much greater in close communication between clinical scientists who examine the pathology and basic scientists who study the underlying mechanisms or the effect of a particular etiology in animal models.

Required Author Forms Disclosure forms provided by the authors are available with the online version of this article.

\section{References}

1. Allen KV, Frier BM, Strachan MW. 2004. The relationship between type 2 diabetes and cognitive dysfunction: longitudinal studies and their methodological limitations. Eur J Pharmacol 490: 169-175

2. Amatniek JC, Hauser WA, DelCastillo-Castaneda C, Jacobs DM, Marder K, et al. 2006. Incidence and predictors of seizures in patients with Alzheimer's disease. Epilepsia 47: 867-872

3. Asher G, Gatfield D, Stratmann M, Reinke H, Dibner C, et al. 2008. SIRT1 regulates circadian clock gene expression through PER2 deacetylation. Cell 134: 317-328

4. Baker LD, Cross DJ, Minoshima S, Belongia D, Watson GS, Craft S. 2011. Insulin resistance and Alzheimer-like reductions in regional cerebral glucose metabolism for cognitively normal adults with prediabetes or early type 2 diabetes. Arch Neurol 68: 51-57

5. Balland E, Dam J, Langlet F, Caron E, Steculorum S, et al. 2014. Hypothalamic tanycytes are an ERK-gated conduit for leptin into the brain. Cell Metab 19: 293-301

6. Barriere DA, Noll C, Roussy G, Lizotte F, Kessai A, et al. 2018. Combination of high-fat/high-fructose diet and low-dose streptozotocin to model long-term type-2 diabetes complications. Sci Rep 8: 424

7. Bass J, Takahashi JS. 2010. Circadian integration of metabolism and energetics. Science 330: 1349-1354 
8. Benford H, Bolborea M, Pollatzek E, Lossow K, HermansBorgmeyer I, et al. 2017. A sweet taste receptor-dependent mechanism of glucosensing in hypothalamic tanycytes. Glia 65: 773789

9. Bigalke B, Schreitmuller B, Sopova K, Paul A, Stransky E, et al. 2011. Adipocytokines and CD34 progenitor cells in Alzheimer's disease. PLoS One 6: e20286

10. Bloudek LM, Spackman DE, Blankenburg M, Sullivan SD. 2011. Review and meta-analysis of biomarkers and diagnostic imaging in Alzheimer's disease. J Alzheimers Dis 26: 627-645

11. Boersma GJ, Johansson E, Pereira MJ, Heurling K, Skrtic S, et al. 2018. Altered Glucose Uptake in Muscle, Visceral Adipose Tissue, and Brain Predict Whole-Body Insulin Resistance and may Contribute to the Development of Type 2 Diabetes: A Combined PET/MR Study. Horm Metab Res 50: 627-639

12. Bomfim TR, Forny-Germano L, Sathler LB, Brito-Moreira J, Houzel JC, et al. 2012. An anti-diabetes agent protects the mouse brain from defective insulin signaling caused by Alzheimer's disease- associated Abeta oligomers. J Clin Invest 122: 13391353

13. Bonda DJ, Stone JG, Torres SL, Siedlak SL, Perry G, et al. 2014. Dysregulation of leptin signaling in Alzheimer disease: evidence for neuronal leptin resistance. J Neurochem 128: 162-172

14. Bredesen DE. 2014. Reversal of cognitive decline: a novel therapeutic program. Aging (Albany NY) 6: 707-717

15. Bruning JC, Gautam D, Burks DJ, Gillette J, Schubert M, et al. 2000. Role of brain insulin receptor in control of body weight and reproduction. Science 289: 2122-2125

16. Busche MA, Eichhoff G, Adelsberger H, Abramowski D, Wiederhold KH, et al. 2008. Clusters of hyperactive neurons near amyloid plaques in a mouse model of Alzheimer's disease. Science 321: 1686-1689

17. Byun K, Gil SY, Namkoong C, Youn BS, Huang H, et al. 2014. Clusterin/ApoJ enhances central leptin signaling through Lrp2mediated endocytosis. EMBO Rep 15: 801-808

18. Canabal DD, Song Z, Potian JG, Beuve A, McArdle JJ, Routh VH. 2007. Glucose, insulin, and leptin signaling pathways modulate nitric oxide synthesis in glucose-inhibited neurons in the ventromedial hypothalamus. Am J Physiol Regul Integr Comp Physiol 292: R1418-R1428

19. Ceriani MF, Hogenesch JB, Yanovsky M, Panda S, Straume M, Kay SA. 2002. Genome-wide expression analysis in Drosophila reveals genes controlling circadian behavior. J Neurosci 22: 93059319

20. Cirrito JR, Yamada KA, Finn MB, Sloviter RS, Bales KR, et al. 2005. Synaptic activity regulates interstitial fluid amyloid-beta levels in vivo. Neuron 48: 913-922

21. Cohen E, Paulsson JF, Blinder P, Burstyn-Cohen T, Du D, et al. 2009. Reduced IGF-1 signaling delays age-associated proteotoxicity in mice. Cell 139: 1157-1169

22. De Santi S, de Leon MJ, Rusinek H, Convit A, Tarshish CY, et al. 2001. Hippocampal formation glucose metabolism and volume losses in MCI and AD. Neurobiol Aging 22: 529-539

23. Di Spiezio A, Sandin ES, Dore R, Muller-Fielitz H, Storck SE, et al. 2018. The LepR-mediated leptin transport across brain barriers controls food reward. Mol Metab 8: 13-22

24. Diaz-Garcia CM, Mongeon R, Lahmann C, Koveal D, Zucker H, Yellen G. 2017. Neuronal Stimulation Triggers Neuronal Glycolysis and Not Lactate Uptake. Cell Metab 26: 361-374 e4

25. Drzezga A, Altomare D, Festari C, Arbizu J, Orini S, et al. 2018. Diagnostic utility of 18 F-Fluorodeoxyglucose positron emission tomography (FDG-PET) in asymptomatic subjects at increased risk for Alzheimer's disease. Eur J Nucl Med Mol Imaging 45: $1487-1496$
26. Ebling FJP, Lewis JE. 2018. Tanycytes and hypothalamic control of energy metabolism. Glia 66: 1176-1184

27. Eckel-Mahan K, Sassone-Corsi P. 2013. Metabolism and the circadian clock converge. Physiol Rev 93: 107-135

28. Frederich RC, Hamann A, Anderson S, Lollmann B, Lowell BB, Flier JS. 1995. Leptin levels reflect body lipid content in mice: evidence for diet-induced resistance to leptin action. Nat Med 1: $1311-1314$

29. Froy O. 2007. The relationship between nutrition and circadian rhythms in mammals. Front Neuroendocrinol 28: 61-71

30. Garcia-Caceres C, Quarta C, Varela L, Gao Y, Gruber T, et al. 2016. Astrocytic Insulin Signaling Couples Brain Glucose Uptake with Nutrient Availability. Cell 166: 867-880

31. Garris DR, Williams SK, Coleman DL, Morgan CR. 1984. Glucose utilization by the mouse brain: influence of age and diabetes. Brain Res 317: 141-146

32. Genin E, Hannequin D, Wallon D, Sleegers K, Hiltunen M, et al. 2011. APOE and Alzheimer disease: a major gene with semidominant inheritance. Mol Psychiatry 16: 903-907

33. German JP, Thaler JP, Wisse BE, Oh IS, Sarruf DA, et al. 2011. Leptin activates a novel CNS mechanism for insulin-independent normalization of severe diabetic hyperglycemia. Endocrinology 152: 394-404

34. Goertzen AL, Bao Q, Bergeron M, Blankemeyer E, Blinder S, et al. 2012. NEMA NU 4-2008 comparison of preclinical PET imaging systems. J Nucl Med 53: 1300-1309

35. Gotz J, Ittner LM. 2008. Animal models of Alzheimer's disease and frontotemporal dementia. Nat Rev Neurosci 9: 532-544

36. Griffin RJ, Moloney A, Kelliher M, Johnston JA, Ravid R, et al. 2005. Activation of Akt/PKB, increased phosphorylation of Akt substrates and loss and altered distribution of Akt and PTEN are features of Alzheimer's disease pathology. J Neurochem 93: 105117

37. Guertin AD, Zhang DP, Mak KS, Alberta JA, Kim HA. 2005. Microanatomy of axon/glial signaling during Wallerian degeneration. J Neurosci 25: 3478-3487

38. Guha A, Vasconcelos M, Cai Y, Yoneda M, Hinds A, et al. 2012. Neuroepithelial body microenvironment is a niche for a distinct subset of Clara-like precursors in the developing airways. Proc Natl Acad Sci U S A 109: 12592-12597

39. Haaksma ML, Vilela LR, Marengoni A, Calderon-Larranaga A, Leoutsakos JS, et al. 2017. Comorbidity and progression of late onset Alzheimer's disease: A systematic review. PLoS One 12: e 0177044

40. Halaas JL, Gajiwala KS, Maffei M, Cohen SL, Chait BT, et al. 1995. Weight-reducing effects of the plasma protein encoded by the obese gene. Science 269: 543-546

41. Hauser WA, Morris ML, Heston LL, Anderson VE. 1986. Seizures and myoclonus in patients with Alzheimer's disease. Neurology 36: 1226-1230

42. Hesdorffer DC, Hauser WA, Annegers JF, Kokmen E, Rocca WA. 1996. Dementia and adult-onset unprovoked seizures. Neurology 46: 727-730

43. Hileman SM, Pierroz DD, Masuzaki H, Bjorbaek C, ElHaschimi K, et al. 2002. Characterizaton of short isoforms of the leptin receptor in rat cerebral microvessels and of brain uptake of leptin in mouse models of obesity. Endocrinology 143: 775-783

44. Holden KF, Lindquist K, Tylavsky FA, Rosano C, Harris TB, et al. 2009. Serum leptin level and cognition in the elderly: Findings from the Health ABC Study. Neurobiol Aging 30: 1483-1489

45. Hollingworth P, Harold D, Sims R, Gerrish A, Lambert JC, et al. 2011. Common variants at ABCA7, MS4A6A/MS4A4E, EPHA1, CD33 and CD2AP are associated with Alzheimer's disease. Nat Genet 43: 429-435 
46. Holth JK, Fritschi SK, Wang C, Pedersen NP, Cirrito JR, et al. 2019. The sleep-wake cycle regulates brain interstitial fluid tau in mice and CSF tau in humans. Science 363: 880-884

47. Holtzman DM, Morris JC, Goate AM. 2011. Alzheimer's disease: the challenge of the second century. Sci Transl Med 3: 77sr1

48. Ishii M, Wang G, Racchumi G, Dyke JP, Iadecola C. 2014. Transgenic mice overexpressing amyloid precursor protein exhibit early metabolic deficits and a pathologically low leptin state associated with hypothalamic dysfunction in arcuate neuropeptide $\mathrm{Y}$ neurons. J Neurosci 34: 9096-9106

49. Jack CR, Jr., Bennett DA, Blennow K, Carrillo MC, Dunn B, et al. 2018. NIA-AA Research Framework: Toward a biological definition of Alzheimer's disease. Alzheimers Dement 14: 535-562

50. Jack CR, Jr., Knopman DS, Jagust WJ, Petersen RC, Weiner MW, et al. 2013. Tracking pathophysiological processes in Alzheimer's disease: an updated hypothetical model of dynamic biomarkers. Lancet Neurol 12: 207-216

51. Johnston JM, Hu WT, Fardo DW, Greco SJ, Perry G, et al. 2014. Low plasma leptin in cognitively impaired ADNI subjects: gender differences and diagnostic and therapeutic potential. Curr Alzheimer Res 11: 165-174

52. Kamenetz F, Tomita T, Hsieh H, Seabrook G, Borchelt D, et al. 2003. APP processing and synaptic function. Neuron 37: 925-937

53. Kang JE, Lim MM, Bateman RJ, Lee JJ, Smyth LP, et al. 2009. Amyloid-beta dynamics are regulated by orexin and the sleepwake cycle. Science 326: 1005-1007

54. Karlsson BH, Knutsson AK, Lindahl BO, Alfredsson LS. 2003. Metabolic disturbances in male workers with rotating three-shift work. Results of the WOLF study. Int Arch Occup Environ Health 76: 424-430

55. Kawachi I, Colditz GA, Stampfer MJ, Willett WC, Manson JE, et al. 1995. Prospective study of shift work and risk of coronary heart disease in women. Circulation 92: 3178-3182

56. Khemka VK, Bagchi D, Bandyopadhyay K, Bir A, Chattopadhyay M, et al. 2014. Altered serum levels of adipokines and insulin in probable Alzheimer's disease. J Alzheimers Dis 41: $525-533$

57. Kleinridders A. 2016. Deciphering Brain Insulin Receptor and Insulin-Like Growth Factor 1 Receptor Signalling. $J$ Neuroendocrinol 28

58. Kuntner C, Kesner AL, Bauer M, Kremslehner R, Wanek T, et al. 2009. Limitations of small animal PET imaging with $[18 \mathrm{~F}]$ FDDNP and FDG for quantitative studies in a transgenic mouse model of Alzheimer's disease. Mol Imaging Biol 11: 236-240

59. la Fleur SE, Kalsbeek A, Wortel J, Fekkes ML, Buijs RM. 2001a. A daily rhythm in glucose tolerance: a role for the suprachiasmatic nucleus. Diabetes 50: 1237-1243

60. la Fleur SE, Kalsbeek A, Wortel J, van der Vliet J, Buijs RM. 2001b. Role for the pineal and melatonin in glucose homeostasis: pinealectomy increases night-time glucose concentrations. $J$ Neuroendocrinol 13: 1025-1032

61. Lambert JC, Ibrahim-Verbaas CA, Harold D, Naj AC, Sims R, et al. 2013. Meta-analysis of 74,046 individuals identifies 11 new susceptibility loci for Alzheimer's disease. Nat Genet 45: $1452-1458$

62. Lamia KA, Sachdeva UM, DiTacchio L, Williams EC, Alvarez JG, et al. 2009. AMPK regulates the circadian clock by cryptochrome phosphorylation and degradation. Science 326: $437-440$

63. Lancelot S, Zimmer L. 2010. Small-animal positron emission tomography as a tool for neuropharmacology. Trends Pharmacol Sci 31: 411-417

64. Landau SM, Harvey D, Madison CM, Reiman EM, Foster NL, et al. 2010. Comparing predictors of conversion and decline in mild cognitive impairment. Neurology 75: 230-238
65. Lane-Donovan C, Herz J. 2017. ApoE, ApoE Receptors, and the Synapse in Alzheimer's Disease. Trends Endocrinol Metab 28: 273-284

66. Langmesser S, Albrecht U. 2006. Life time-circadian clocks, mitochondria and metabolism. Chronobiol Int 23: 151-157

67. Last D, Alsop DC, Abduljalil AM, Marquis RP, de Bazelaire C, et al. 2007. Global and regional effects of type 2 diabetes on brain tissue volumes and cerebral vasoreactivity. Diabetes Care 30: 1193-1199

68. Lieb W, Beiser AS, Vasan RS, Tan ZS, Au R, et al. 2009. Association of plasma leptin levels with incident Alzheimer disease and MRI measures of brain aging. JAMA 302: 2565-2572

69. Liu CC, Liu CC, Kanekiyo T, Xu H, Bu G. 2013. Apolipoprotein E and Alzheimer disease: risk, mechanisms and therapy. Nat Rev Neurol 9: 106-118

70. Liu Y, Liu F, Grundke-Iqbal I, Iqbal K, Gong CX. 2011. Deficient brain insulin signalling pathway in Alzheimer's disease and diabetes. $J$ Pathol 225: 54-62

71. Lopez-Lopez C, Dietrich MO, Metzger F, Loetscher H, TorresAleman I. 2007. Disturbed cross talk between insulin-like growth factor I and AMP-activated protein kinase as a possible cause of vascular dysfunction in the amyloid precursor protein/presenilin 2 mouse model of Alzheimer's disease. J Neurosci 27: 824-831

72. Lucey BP, Mawuenyega KG, Patterson BW, Elbert DL, Ovod V, et al. 2017. Associations Between beta-Amyloid Kinetics and the beta-Amyloid Diurnal Pattern in the Central Nervous System. JAMA Neurol 74: 207-215

73. Lundgaard I, Li B, Xie L, Kang H, Sanggaard S, et al. 2015. Direct neuronal glucose uptake heralds activity-dependent increases in cerebral metabolism. Nat Commun 6: 6807

74. Luo F, Rustay NR, Ebert U, Hradil VP, Cole TB, et al. 2012. Characterization of 7- and 19-month-old Tg2576 mice using multimodal in vivo imaging: limitations as a translatable model of Alzheimer's disease. Neurobiol Aging 33: 933-944

75. Lutz MW, Sundseth SS, Burns DK, Saunders AM, Hayden KM, et al. 2016. A Genetics-based Biomarker Risk Algorithm for Predicting Risk of Alzheimer's Disease. Alzheimers Dement ( $N$ Y) $2: 30-44$

76. Macauley SL, Stanley M, Caesar EE, Yamada SA, Raichle ME, et al. 2015. Hyperglycemia modulates extracellular amyloid-beta concentrations and neuronal activity in vivo. $J$ Clin Invest 125 : 2463-2467

77. Mairet-Coello G, Courchet J, Pieraut S, Courchet V, Maximov A, Polleux F. 2013. The CAMKK2-AMPK kinase pathway mediates the synaptotoxic effects of Abeta oligomers through Tau phosphorylation. Neuron 78: 94-108

78. Martin-Moreno AM, Brera B, Spuch C, Carro E, Garcia-Garcia L, et al. 2012. Prolonged oral cannabinoid administration prevents neuroinflammation, lowers beta-amyloid levels and improves cognitive performance in Tg APP 2576 mice. J Neuroinflammation 9: 8

79. Matschinsky FM. 1990. Glucokinase as glucose sensor and metabolic signal generator in pancreatic beta-cells and hepatocytes. Diabetes 39: 647-652

80. McNay EC, Recknagel AK. 2011. Brain insulin signaling: a key component of cognitive processes and a potential basis for cognitive impairment in type 2 diabetes. Neurobiol Learn Mem 96: 432-442

81. Mendez M, Lim G. 2003. Seizures in elderly patients with dementia: epidemiology and management. Drugs Aging 20: 791-803

82. Minokoshi Y, Alquier T, Furukawa N, Kim YB, Lee A, et al. 2004. AMP-kinase regulates food intake by responding to hormonal and nutrient signals in the hypothalamus. Nature 428: 569-574

83. Minoshima S, Giordani B, Berent S, Frey KA, Foster NL, Kuhl DE. 1997. Metabolic reduction in the posterior cingulate cortex in very early Alzheimer's disease. Ann Neurol 42: 85-94 
84. Mosconi L. 2005. Brain glucose metabolism in the early and specific diagnosis of Alzheimer's disease. FDG-PET studies in MCI and AD. Eur J Nucl Med Mol Imaging 32: 486-510

85. Mosconi L, Brys M, Glodzik-Sobanska L, De Santi S, Rusinek H, de Leon MJ. 2007. Early detection of Alzheimer's disease using neuroimaging. Exp Gerontol 42: 129-138

86. Mosconi L, De Santi S, Li Y, Li J, Zhan J, et al. 2006. Visual rating of medial temporal lobe metabolism in mild cognitive impairment and Alzheimer's disease using FDG-PET. Eur J Nucl Med Mol Imaging 33: 210-221

87. Nakahata Y, Kaluzova M, Grimaldi B, Sahar S, Hirayama J, et al. 2008. The NAD+-dependent deacetylase SIRT1 modulates CLOCK-mediated chromatin remodeling and circadian control. Cell 134: 329-340

88. Nestor PJ, Fryer TD, Smielewski P, Hodges JR. 2003. Limbic hypometabolism in Alzheimer's disease and mild cognitive impairment. Ann Neurol 54: 343-351

89. Oosterman JE, Kalsbeek A, la Fleur SE, Belsham DD. 2015. Impact of nutrients on circadian rhythmicity. Am J Physiol Regul Integr Comp Physiol 308: R337-R350

90. Palop JJ, Mucke L. 2009. Epilepsy and cognitive impairments in Alzheimer disease. Arch Neurol 66: 435-440

91. Panda S, Antoch MP, Miller BH, Su AI, Schook AB, et al. 2002. Coordinated transcription of key pathways in the mouse by the circadian clock. Cell 109: 307-320

92. Parent MJ, Zimmer ER, Shin M, Kang MS, Fonov VS, et al. 2017. Multimodal Imaging in Rat Model Recapitulates Alzheimer's Disease Biomarkers Abnormalities. J Neurosci 37: 12263-12271

93. Parkes KR. 2002. Shift work and age as interactive predictors of body mass index among offshore workers. Scand $J$ Work Environ Health 28: 64-71

94. Pei JJ, Khatoon S, An WL, Nordlinder M, Tanaka T, et al. 2003. Role of protein kinase B in Alzheimer's neurofibrillary pathology. Acta Neuropathol 105: 381-392

95. Peila R, Rodriguez BL, Launer LJ, Honolulu-Asia Aging S. 2002. Type 2 diabetes, APOE gene, and the risk for dementia and related pathologies: The Honolulu-Asia Aging Study. Diabetes 51: 1256 1262

96. Placais PY, de Tredern E, Scheunemann L, Trannoy S, Goguel V, et al. 2017. Upregulated energy metabolism in the Drosophila mushroom body is the trigger for long-term memory. Nat Commun 8: 15510

97. Power DA, Noel J, Collins R, O'Neill D. 2001. Circulating leptin levels and weight loss in Alzheimer's disease patients. Dement Geriatr Cogn Disord 12: 167-170

98. Prinz PN, Peskind ER, Vitaliano PP, Raskind MA, Eisdorfer C, et al. 1982a. Changes in the sleep and waking EEGs of nondemented and demented elderly subjects. J Am Geriatr Soc 30: 86-93

99. Prinz PN, Vitaliano PP, Vitiello MV, Bokan J, Raskind M, et al. 1982b. Sleep, EEG and mental function changes in senile dementia of the Alzheimer's type. Neurobiol Aging 3: 361-370

100. Rabinovici GD, Jagust WJ, Furst AJ, Ogar JM, Racine CA, et al. 2008. Abeta amyloid and glucose metabolism in three variants of primary progressive aphasia. Ann Neurol 64: 388-401

101. Rabinovici GD, Rosen HJ, Alkalay A, Kornak J, Furst AJ, et al. 2011. Amyloid vs FDG-PET in the differential diagnosis of AD and FTLD. Neurology 77: 2034-2042

102. Raikwar SP, Bhagavan SM, Ramaswamy SB, Thangavel R, Dubova I, et al. 2018. Are Tanycytes the Missing Link Between Type 2 Diabetes and Alzheimer's Disease? Mol Neurobiol

103. Rapic S, Backes H, Viel T, Kummer MP, Monfared P, et al. 2013. Imaging microglial activation and glucose consumption in a mouse model of Alzheimer's disease. Neurobiol Aging 34: 351354

104. Reiman EM, Caselli RJ, Yun LS, Chen K, Bandy D, et al. 1996. Preclinical evidence of Alzheimer's disease in persons homozygous for the epsilon 4 allele for apolipoprotein E. $N$ Engl J Med 334: 752-758

105. Robins SC, Stewart I, McNay DE, Taylor V, Giachino C, et al. 2013. alpha-Tanycytes of the adult hypothalamic third ventricle include distinct populations of FGF-responsive neural progenitors. Nat Commun 4: 2049

106. Rodriguez EM, Blazquez JL, Pastor FE, Pelaez B, Pena P, et al. 2005. Hypothalamic tanycytes: a key component of brainendocrine interaction. Int Rev Cytol 247: 89-164

107. Roh JH, Huang Y, Bero AW, Kasten T, Stewart FR, et al. 2012. Disruption of the sleep-wake cycle and diurnal fluctuation of betaamyloid in mice with Alzheimer's disease pathology. Sci Transl Med 4: 150ra22

108. Romanelli MF, Morris JC, Ashkin K, Coben LA. 1990. Advanced Alzheimer's disease is a risk factor for late-onset seizures. Arch Neurol 47: 847-850

109. Saunders AM, Strittmatter WJ, Schmechel D, George-Hyslop PH, Pericak-Vance MA, et al. 1993. Association of apolipoprotein E allele epsilon 4 with late-onset familial and sporadic Alzheimer's disease. Neurology 43: 1467-1472

110. Scarmeas N, Honig LS, Choi H, Cantero J, Brandt J, et al. 2009. Seizures in Alzheimer disease: who, when, and how common? Arch Neurol 66: 992-997

111. Scholl M, Damian A, Engler H. 2014. Fluorodeoxyglucose PET in Neurology and Psychiatry. PET Clin 9: 371-390, v

112. Selkoe DJ, Yamazaki T, Citron M, Podlisny MB, Koo EH, et al. 1996. The role of APP processing and trafficking pathways in the formation of amyloid beta-protein. Ann N Y Acad Sci 777: 57-64

113. Shibata M, Yasuda B. 1980. New experimental congenital diabetic mice (N.S.Y. mice). Tohoku J Exp Med 130: 139-142

114. Silverman DH, Small GW, Chang CY, Lu CS, Kung De Aburto MA, et al. 2001. Positron emission tomography in evaluation of dementia: Regional brain metabolism and long-term outcome. JAMA 286: 2120-2127

115. Silverman DH, Small GW, Phelps ME. 1999. Clinical Value of Neuroimaging in the Diagnosis of Dementia. Sensitivity and Specificity of Regional Cerebral Metabolic and Other Parameters for Early Identification of Alzheimer's Disease. Clin Positron Imaging 2: 119-130

116. Sims-Robinson C, Kim B, Rosko A, Feldman EL. 2010. How does diabetes accelerate Alzheimer disease pathology? Nat Rev Neurol 6: 551-559

117. Snider BJ, Fagan AM, Roe C, Shah AR, Grant EA, et al. 2009. Cerebrospinal fluid biomarkers and rate of cognitive decline in very mild dementia of the Alzheimer type. Arch Neurol 66: 638645

118. Son SM, Jung ES, Shin HJ, Byun J, Mook-Jung I. 2012. Abetainduced formation of autophagosomes is mediated by RAGECaMKKbeta-AMPK signaling. Neurobiol Aging 33: 1006 e11e23

119. Song H, Moon M, Choe HK, Han DH, Jang C, et al. 2015. Abetainduced degradation of BMAL1 and CBP leads to circadian rhythm disruption in Alzheimer's disease. Mol Neurodegener 10: 13

120. Stanley M, Macauley SL, Holtzman DM. 2016. Changes in insulin and insulin signaling in Alzheimer's disease: cause or consequence? J Exp Med 213: 1375-1385

121. Steen E, Terry BM, Rivera EJ, Cannon JL, Neely TR, et al. 2005. Impaired insulin and insulin-like growth factor expression and signaling mechanisms in Alzheimer's disease-is this type 3 diabetes? J Alzheimers Dis 7: 63-80 
122. Steinbusch L, Labouebe G, Thorens B. 2015. Brain glucose sensing in homeostatic and hedonic regulation. Trends Endocrinol Metab 26: 455-466

123. Sterniczuk R, Dyck RH, Laferla FM, Antle MC. 2010. Characterization of the 3xTg-AD mouse model of Alzheimer's disease: part 1. Circadian changes. Brain Res 1348: 139-148

124. Stohr O, Schilbach K, Moll L, Hettich MM, Freude S, et al. 2013. Insulin receptor signaling mediates APP processing and betaamyloid accumulation without altering survival in a transgenic mouse model of Alzheimer's disease. Age (Dordr) 35: 83-101

125. Takeda S, Sato N, Uchio-Yamada K, Sawada K, Kunieda T, et al. 2010. Diabetes-accelerated memory dysfunction via cerebrovascular inflammation and Abeta deposition in an Alzheimer mouse model with diabetes. Proc Natl Acad Sci U S A 107: 7036-7041

126. Talbot K, Wang HY, Kazi H, Han LY, Bakshi KP, et al. 2012. Demonstrated brain insulin resistance in Alzheimer's disease patients is associated with IGF-1 resistance, IRS-1 dysregulation, and cognitive decline. J Clin Invest 122: 1316-1338

127. Terauchi Y, Sakura H, Yasuda K, Iwamoto K, Takahashi N, et al. 1995. Pancreatic beta-cell-specific targeted disruption of glucokinase gene. Diabetes mellitus due to defective insulin secretion to glucose. J. Biol. Chem. 270: 30253-30256

128. Thornton C, Bright NJ, Sastre M, Muckett PJ, Carling D. 2011. AMP-activated protein kinase (AMPK) is a tau kinase, activated in response to amyloid beta-peptide exposure. Biochem $J$ 434: 503-512

129. Unger JW, Livingston JN, Moss AM. 1991a. Insulin receptors in the central nervous system: localization, signalling mechanisms and functional aspects. Prog Neurobiol 36: $343-362$

130. Unger JW, Moss AM, Livingston JN. $1991 \mathrm{~b}$. Immunohistochemical localization of insulin receptors and phosphotyrosine in the brainstem of the adult rat. Neuroscience 42: $853-861$

131. van Amelsvoort LG, Schouten EG, Kok FJ. 1999. Duration of shiftwork related to body mass index and waist to hip ratio. Int $J$ Obes Relat Metab Disord 23: 973-978

132. Vandal M, White PJ, Chevrier G, Tremblay C, St-Amour I, et al. 2015. Age-dependent impairment of glucose tolerance in the 3xTg-AD mouse model of Alzheimer's disease. FASEB $J$ 29: 4273-4284

133. Vannucci SJ, Gibbs EM, Simpson IA. 1997. Glucose utilization and glucose transporter proteins GLUT-1 and GLUT-3 in brains of diabetic (db/db) mice. Am J Physiol 272: E267-E274

134. Willette AA, Bendlin BB, Starks EJ, Birdsill AC, Johnson SC, et al. 2015. Association of Insulin Resistance With Cerebral Glucose Uptake in Late Middle-Aged Adults at Risk for Alzheimer Disease. JAMA Neurol 72: 1013-1020

135. Williams T, Courchet J, Viollet B, Brenman JE, Polleux F. 2011. AMP-activated protein kinase (AMPK) activity is not required for neuronal development but regulates axogenesis during metabolic stress. Proc Natl Acad Sci U S A 108: $5849-5854$

136. Wyss MT, Jolivet R, Buck A, Magistretti PJ, Weber B. 2011. In vivo evidence for lactate as a neuronal energy source. $J$ Neurosci 31: 7477-7485

137. Xie L, Kang H, Xu Q, Chen MJ, Liao Y, et al. 2013. Sleep drives metabolite clearance from the adult brain. Science 342: $373-377$

138. Yamamoto K, Tanei ZI, Hashimoto T, Wakabayashi T, Okuno H, et al. 2015. Chronic optogenetic activation augments abeta pathology in a mouse model of Alzheimer disease. Cell Rep 11: 859-865

139. Yarchoan M, Toledo JB, Lee EB, Arvanitakis Z, Kazi H, et al. 2014. Abnormal serine phosphorylation of insulin receptor substrate 1 is associated with tau pathology in Alzheimer's disease and tauopathies. Acta Neuropathol 128: 679-689

140. Yi D, Lee DY, Sohn BK, Choe YM, Seo EH, et al. 2014. Betaamyloid associated differential effects of APOE epsilon 4 on brain metabolism in cognitively normal elderly. Am J Geriatr Psychiatry 22: 961-970

141. Yin H, Tian S, Huang R, Cai R, Guo D, et al. 2018. Low Plasma Leptin and High Soluble Leptin Receptor Levels Are Associated With Mild Cognitive Impairment in Type 2 Diabetic Patients. Front Aging Neurosci 10: 132

142. Yoon So, Park, D.J., Ryu, J.C., Ozer, H.G., Tep, C., Shin, Y.J., Lim, T.H., Pastorino, L., Kunwar, A.J., Walton, J.C., Nagahara, A.H., Lu, K.P., Nelson, R.J., Tuszynski, M.H., Huan, K. 2012. JNK3 perpetuates metabolic stress induced by Abeta peptides. Neuron 75: 824

143. Yuan SM, Gao K, Wang DM, Quan XZ, Liu JN, et al. 2011. Evodiamine improves congnitive abilities in SAMP8 and APP (swe)/PS1(DeltaE9) transgenic mouse models of Alzheimer's disease. Acta Pharmacol Sin 32: 295-302

144. Zhao N, Liu CC, Van Ingelgom AJ, Martens YA, Linares C, et al. 2017. Apolipoprotein E4 Impairs Neuronal Insulin Signaling by Trapping Insulin Receptor in the Endosomes. Neuron 96: 115-129 e5

145. Zhou L, Gao Q, Nie M, Gu JL, Hao W, et al. 2016. Degeneration and energy shortage in the suprachiasmatic nucleus underlies the circadian rhythm disturbance in ApoE(-/-) mice: implications for Alzheimer's disease. Sci Rep 6: 36335

146. Zimmer ER, Parent MJ, Cuello AC, Gauthier S, Rosa-Neto P. 2014. MicroPET imaging and transgenic models: a blueprint for Alzheimer's disease clinical research. Trends Neurosci 37: 629641

147. Zimmer ER, Parent MJ, Souza DG, Leuzy A, Lecrux C, et al. 2017. [(18)F] FDG PET signal is driven by astroglial glutamate transport. Nat Neurosci 20: 393-395

Publisher's Note Springer Nature remains neutral with regard to jurisdictional claims in published maps and institutional affiliations. 